\title{
Principales tendencias de variación en los ecosistemas lóticos de Sierra Nevada
}

\author{
C. Canteras Jordana ${ }^{1}, L$. Ropero García
}

Universidad de Granada. Facultad de Ciencias. Dpto. de Ecología. Granada.

1 Dirección actual: Cátedra de Ecología. ETS Ingenieros Caminos Canales y Puertos. Avenida de los Castros s/n. Santander.

\section{SUMMARY}

MAIN VARIATION TENDENCES IN THE LOTIC ECOSYSTEMS FROM SIERRA NEVADA (GRANADA, S-SPAIN)

Physical, chemical and biological characteristics were studied from sixty-one samples taken in seven rivers of Sierra Nevada (S. Spain). Sampling took place in twenty-one stations from November 1980 to June 1981.

The results obtained showed a progress've increase of mineral salt content, heterotrophic bacterial populations, coliform density, soluble phosphate and nitrate concentrations, and Margalef pigment index, according as the altitude decrease, specially down rivers from 800 meters, whereas the oxygen concentration decreased.

A principal component analysis transformed the original variables into five new variables which accounted for $82,3 \%$ of the total variance of the data. The interpretation of the five principal components is as follows: 1st, organic contamination; 2 nd, water mineralisation; $3 \mathrm{rd}$, phaecal pollution; 4 th, water acidity degree; 5 th, water velocity.

\section{INTRODUCCION}

Sierra Nevada es, gracias a sus nieves, una gran reserva de agua y proporciona el agua a la Vega granadina y prácticamente a todo el sureste de Andalucía. Pero, además, es soporte único en la Península, junto con los Pirineos, de ecosistemas de alta montaña. Debido a su situación geográfica posee peculiaridades propias gracias a las cuales encontramos una gran variedad de especies endémicas, fruto de una gran variedad de microclimas.
En general, el creciente desarrollo de la actividad humana sobre esta zona tiene un claro reflejo en la calidad y composición química de las aguas. Asi en alguno de sus rios, como el Monachil, en la cabecera se encuentran urbanizaciones cuyas aguas residuales se vierten directamente sobre el rio.

Este trabajo tiene por objeto efectuar una evaluación de las tendencias de variación actuales en los sistemas lóticos de Sierra Nèvada, sobre la base de un muestreo en siete de los principales cursos fluviales de la sierra, con veintiuna estaciones de muestreo situa- 

(1978) y de SHWOERBEL (1975) basadas

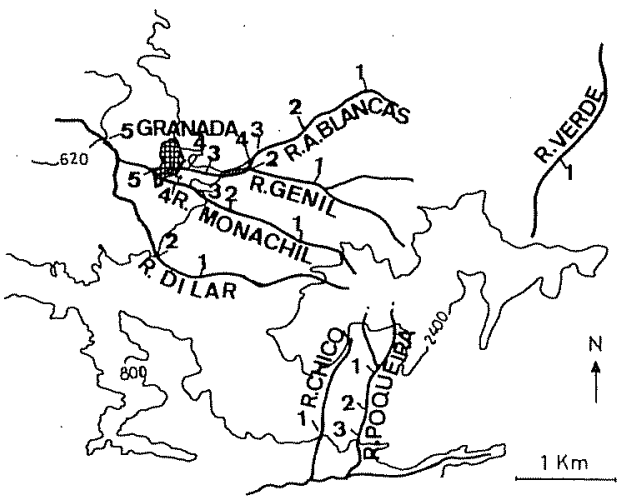

Fig. 1. Mapa de distribución de las estaciones de muestreo.

\section{MATERIAL Y METODOS}

En el periodo comprendido entre noviembre de 1980 y junio de 1981 se tomaron 61 muestras de agua, distribuidas en los períodos de otoño, invierno y primavera.

Los ríos estudiados y la ubicación de las distintas estaciones de muestreo se presentan en la figura 1. En los ríos Genil y Monachil se situaron cinco estaciones entre los $1.600 \mathrm{y}$ 620 metros de altitud. El río Aguas Blancas fue muestreado en cuatro puntos a 1.300 , $1.200,800$ y 740 metros y el río Dílar en dos a 1.000 y 800 metros. Los ríos de la vertiente Sur, Poqueira y Chico, por su menor extensión y caudal fueron estudiados tan sólo en altitudes de 1.600 y 900 metros. Por último, en el río Verde se situó una estación a 1.300 metros.

En cada muestra se realizó el estudio de un conjunto de parámetros físicos, químicos $\mathrm{y}$ bióticos.

Los parámetros físicos medidos fueron los siguientes: temperatura, turbidez, caudal $y$ velocidad del agua. La temperatura -con el oxígeno disuelto, la conductividad y el pH- fue medida con una sonda Hidrolab digital 4041. Para la estimación de la velocidad de la corriente y del caudal se siguieron las en controlar el tiempo invertido por un flotador en recorrer una distancia conocida.

Para la caracterización química de las aguas se midieron los cationes calcio, magnesio, potasio y sodio y los siguientes aniones: cloruros, silicatos, fosfatos, nitratos, nitritos y sulfatos. Los cationes se determinaron por espectrofotometría de absorción atómica (RODIER, 1978) y los aniones siguiendo los métodos desarrollados por el Departamento de Ecología de la Universidad de Barcelona (MARGALEF et al., 1976; ROS, 1979).

El grado de contaminación orgánica se estimó midiendo la demanda química y biológica de oxígeno (GOLTERMAN, 1969), déficit de oxígeno (RODIER, 1978), concentración de amonio (ROS, 1979) y la estabilidad relativa del agua (CATALAN, 1969).

La determinación de la clorofila "a" y del indice de Margalef y la enumeración de bacterias heterótrofas y de Escherichia coli constituyeron los parámetros bióticos medidos. La extracción y medida de los pigmentos se hizo siguiendo los criterios de ROS (1979). Los ensayos de colimetría se efectuaron en medio líquido (HARRIGAN \& McCANCE, 1968; GUINEA et. al., 1979). La identificación de $E$. coli se hizo mediante las reacciones del IMViC y la prueba de Eijman (RODINA, 1972). El recuento de bacterias heterótrofas se efectuó según el método de siembra en placa (SOROKIN \& KADOTA, 1972), con un medio de cultivo de peptona-extracto de levadura. La temperatura de incubación fue de $20^{\circ} \mathrm{C}$ durante un período de tiempo de diez dias.

En un muestreo de estas características (que se realizó sobre distintos ríos y se extendió a lo largo del tiempo y del espacio) cada variable estudiada puede diferir segun tres factores o fuentes de variación: Ríos, periodos de muestreo y altitudes. Para decidir acerca de la significación de las diferencias que cada variable puede presentar entre los distintos ríos, distintos períodos de muestreo y distintas altitudes, se realizó para cada una un análisis factorial jerarquizado sobre el que se efectuó el análisis de la varianza (GRAYBILL, 1961; CHING CHUN LI, 
1969). La relación entre las distintas variables se estudió mediante el análisis de correlación simple y las principales tendencias de variación se pusieron de manifiesto aplicando un análisis de componentes principales a los valores medios de los parámetros estudiados, previa transformación logarítmica, según el paquete de programas del BMDP en su versión 75 y más concretamente el programa P4M.

\section{RESULTADOS}

\section{PARAMETROS FISICOS Y QUIMICOS}

El régimen fluvial de los ríos estudiados es de tipo mediterráneo subtropical, caracterizados por un máximo en marzo-abril, con una fuerte acción nival, un profundo estiaje en verano y un ligero mínimo secundario en enero.

En general, por encima de los 1.000 metros de altitud sobre el nivel del mar la corriente es rápida (velocidad del agua comprendida entre 50 y $100 \mathrm{~cm} / \mathrm{s}$ ) o muy rápida (superior a $100 \mathrm{~cm} / \mathrm{s}$ ). Por debajo de los 620 metros la velocidad resulta más lenta (inferior a 50 $\mathrm{cm} / \mathrm{s}$ ) con valores elevados de turbidez.

La conductividad eléctrica ilustra el grado de mineralización del agua que se debió en parte a la naturaleza geológica por donde discurren los ríos y a determinados vertidos procedentes de la actividad humana, principalmente aguas abajo de los 800 metros de altitud. Estas circunstancias propiciaron una fuerte correlación negativa entre este parámetro y la altitud (fig. 2).

La temperatura del agua varió entre 3,4 y $20^{\circ} \mathrm{C}$ con una oscilación de los valores medios entre 7 y $12^{\circ} \mathrm{C}$. Se correlacionó positivamente con la alcalinidad y con las concentraciones de magnesio, calcio y nitritos. Negativamente con la altitud, caudal y concentración de oxígeno. La significación de estas correlaciones fueron, en todos los casos, superiores al $95 \%$.

\section{ALCALINIDAD y $\mathrm{pH}$}

La reserva alcalina mostró valores diversos según la altitud de las estaciones de muestreo. En valor medio, estuvo comprendida entre $0,5 \mathrm{meq} / 1$ (estación 1 del río Genil) y $5,2 \mathrm{meq} / \mathrm{l}$ (estaciones 4 y 5 del río Genil). Según los valores de $\mathrm{pH}$ del agua, la mayor parte de la alcalinidad se debió a los bicarbonatos.

El pH varió entre 6,1 (estación 1 del río Genil) y 9,8 (estaciones 4 y 5 del río Monachil), estando el $76,6 \%$ de las medidas efectuadas entre 7 y 8 . En altitudes superiores a los 800 metros las aguas resultaron neutras y ligeramente alcalinas aguas abajo de $\operatorname{los} 740$ metros de altitud.

Los análisis de varianza revelan que sólo existen diferencias significativas $(\mathrm{P}<0,001)$ entre las distintas altitudes. Se puede afirmar, por tanto, que con independencia de los distintos períodos de muestreo y de los diferentes rios, las aguas de altitudes inferiores son más básicas y poseen mayor reserva alcalina que las aguas de altitudes superiores.

\section{CATIONES}

Los cationes monovalentes - sodio y potasio- fueron en todo momento minoritarios frente a los divalentes. Su distribución dependió fundamentalmente de la altitud y del período de muestreo, con los valores más elevados en la muestra invernal y en las estaciones de muestreo de menor altitud.

En general, los ríos de la vertiente Noroeste fueron los que presentaron los niveles de calcio más elevados. Las diferencias entre altitudes no resultaron significativas y el comportamiento del calcio fue diferente según los ríos. En el Genil la concentración aumentó desde la primera a la última estación, mientras que en el rio Aguas Blancas sucedió todo lo contrario. En el río Poqueira, en cambio, no se encontró diferencias significativas entre sus tres estaciones de muestreo. El magnesio presentó una distribución semejante a la del calcio. 


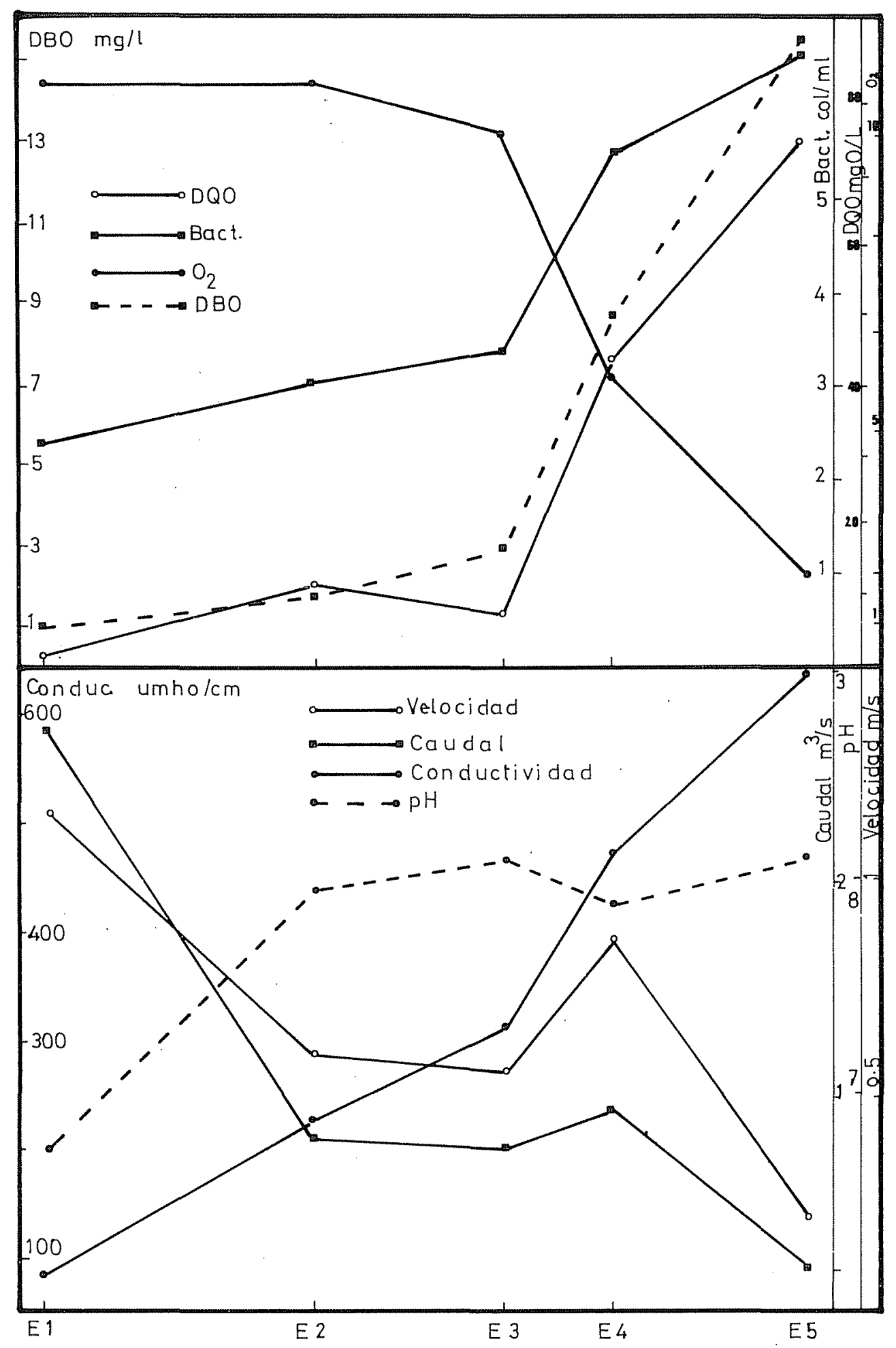

Fig. 2. Variación de algunos parámetros físicos e indicadores de materia orgánica en el río Genil. 
Los cationes mostraron una amplia gama de correlaciones significativas $(\mathrm{P}<0,05)$ con las restantes variables definidoras de la mineralización (conductividad y alcalinidad) (tabla I).

TABLA I. Matriz de coeficientes de correlación entre los cationes y los diferentes parámetros medidos con un nivel de significación $P<0,05$.

Oxígeno

Corrductividad

Déficit $\mathrm{O}_{2}$

Alcalinidad

Temperatura

Altitud

$$
\begin{array}{lllll}
\mathrm{Na}^{++} & \mathrm{K}^{+} & \mathrm{Mg}^{++} & \mathrm{Ca}^{++} \\
0,81 & 0,84 & 0,45 & 0,51 \\
0,70 & 0,70 & 0,45 & 0,60 \\
0,80 & 0,81 & 0,65 & 0,45 \\
0,59 & 0,63 & 0,64 & 0,75 \\
0,46 & 0,45 & 0,61 & 0,69 \\
0,47 & 0,47 & 0,49 & 0,52
\end{array}
$$

\section{ANIONES}

Los valores de sulfatos presentaron una clara diferencia $(P<0,05)$ entre los períodos de muestreo. Los valores más altos se registraron en la muestra invernal y oscilaron entre $5,8 \mathrm{mg} / \mathrm{l}$, estación 1 del río Poqueira, $y$ $480 \mathrm{mg} / 1$, en la estación $5 \mathrm{del}$ río Genil. En otoño y primavera los valores fueron más bajos, estando comprendidos entre $4,8 \mathrm{mg} / 1$ y $110 \mathrm{mg} / \mathrm{l}$ respectivamente medidos en la estación 1 del río Poqueira y 4 del rio Monachil. En general los valores de sulfatos también variaron con la altitud, con las concentraciones mayores en las estaciones de más baja altitud.

Los cloruros estuvieron comprendidos en un $71 \%$ de los casos entre valores no detectables y $1 \mathrm{meq} / \mathrm{l}$. Los más elevadores se mi-. dieron en las estaciones de muestreo de menor altitud: 4 y 5 del río Genil y 5 del río Monachil, con valores siempre superiores a $10 \mathrm{meq} / \mathrm{l}$.

\section{COMPUESTOS DEL NITROGENO}

Los valores más elevados de concentración de nitratos se obtuvieron en los ríos de la vertiente Noroeste de la sierra, donde por debajo de los 800 metros de altitud se produjo un fuerte incremento de la concentración de nutrientes (fig. 3). El análisis de varianza mostró que las tres fuentes de variación; rios, periodos de muestreo y altitudes, fueron significativas. Asi pues, se puede deducir que durante el otoño y el invierno en altitudes inferiores a los 800 metros y en los ríos Genil, Aguas Blancas y Monachil se presentaron los valores más altos de concentración de nitratos. La correlación con la altitud fue muy significativa con un valor de $-0,70 \cdot(\mathrm{P}<0,01)$.

Los nitritos presentaron un comportamiento semejante al de los nitratos, con una correlación. con la altitud de $-0,58$ ( $\mathrm{P}<$ $0,01)$. También mostraton correlación negativa con el oxígeno disuelto y con la velocidad de la corriente y positiva con las siguientes variables: $E$. coli, bacterias heterótrofas, indice de pigmentos de Margalef, conductividad eléctrica, turbidez del agua y con las concentraciones de sulfatos, sodio y potasio. En todos los casos el nivel de significación fue superior al $95 \%$.

La concentración de amonio fue también en aumento progresivo a medida que los rios discurrían por sus cauces con un indice de correlación con la altitud de $-0,44(\mathrm{P}<$ 0,01 ).

La relación entre el nitrógeno inorgánico soluble total y la altitud se puede resumir en los siguientes términos: Por encima de los 1.300 metros de altitud la concentración fue inferior a 5 microgramos-átomos de nitrógeno por litro, mientras que entre 1.300 y 800 metros estuvo comprendida entre 5 y 20. Entre 800 y 620 metros osciló entre 20 y 70 y por debajo de 620 metros de altitud la concentración de nitrógeno fue superior a 70 microgramos-átomo por litro.

\section{FOSFATOS}

Los valores de fosfatos son claramente ilustrativos de la progresiva eutrofización que están sufriendo las aguas corrientes de Sierra Nevada, especialmente la vertiente 
Noroeste. En el río Genil, por ejemplo, los incrementos respecto de la primera estación, que presentó una concentración media de 0,2 microgramos-átomos de fósforo por litro, fueron los siguientes: Estación 2, 235\%; estación 3, $535 \%$; estación 4, $15.970 \%$; estación 5, 27.650\%. En los rios de la vertiente Sur se obtuvieron los valores más bajos que oscilaron entre 0,13 y 0,47 microgramos-átomos de fósforo por litro.

Del correspondiente análisis de la varianza se puede deducir que las únicas diferencias significativas $(P<0,01)$ son las observadas entre las distintas altintudes.

\section{PARAMETROS INDICADORES DE MATERIA ORGANICA}

Los valores más elevados de oxígeno disuelto correspondieron a la muestra invernal y los más bajos a la de primavera. En los ríos de la vertiente Sur las aguas parecen más oxigenadas y, 'en general, salvo en el río Aguas Blancas, se puede observar una progresiva disminución del oxígeno disuelto en función de la altitud, con la que presentó un índice de correlación de $0,38(\mathrm{P}<0,02)$. Por encima de 1.100 metros la concentración de oxígeno fue superior a $10,5 \mathrm{mg} / 1$. Entre 700 y 1.100 metros varió alrededor de $10 \mathrm{mg} / \mathrm{l}$, siendo inferior a $2 \mathrm{mg} / \mathrm{l}$ aguas abajo de 620 metros de altitud. No existen diferencias significativas entre los diferentes ríos estudiados ni entre los diferentes períodos de muestreo. Así pues, los valores más altos de oxígeno se dieron en las estaciones más elevadas y durante el invierno y se correlacionó negativamente $(\mathrm{P}<0,05)$ con los nitritos, conductividad, indice de Margalef, temperatura, coliformes, bacterias heterótrofas.

La carga orgánica químicamente oxidable (DQO) mostró fuertes variaciones entre altitudes, ríos y períodos de muestreo, aunque estadísticamente sólo puedan admitirse como significativas $(P<0,001)$ las encontradas entre altitudes. En general, en todos los cauces estudiados se apreció un incremento de la DQO a medida que la altitud disminuía. Esta situación fue marcadamente acentuada en los ríos Genil y Monachil (fig. 2). Por debajo de 620 metros se registraron demandas quimicas siempre superiores a $58 \mathrm{mg}$ $\mathrm{O}_{2} / \mathrm{l}$, mientras que por encima de los 1.300 metros de altitud fueron siempre inferiores a $10 \mathrm{mg} 0_{2} / \mathrm{l}$. El indice de correlación con la altitud fue de $-0,46(\mathrm{P}<0,01)$.

$\mathrm{La}$ demanda biológica de oxígeno $\left(\mathrm{DBO}_{5}\right)$ presentó los valores más elevados en los ríos Genil y Monachil y los más bajos en el río Aguas Blancas. Como la demanda química, la biológica fue aumentando a medida que los cauces perdían altitud. Por encima de 1.300 metros de altitud fue siempre inferior a $1,21 \mathrm{mg} \mathrm{O} / \mathrm{l}$, con la excepción de la estación 1 del río Monachil (que a 1.600 metros presentó un valor medio de $2,83 \mathrm{mg} \mathrm{O}_{2} / 1$ ). Las diferencias de $\mathrm{DBO}_{5}$ entre los distintos ríos no resultaron significativas, mientras que sí lo fueron $(\mathrm{P}<0,001)$ las diferencias entre altitudes y entre los distintos períodos de muestreo. En general, por tanto, la demanda biológica fue más elevada en verano y en otoño y en las estaciones de muestreo menos elevadas. $\mathrm{La}^{\mathrm{DBO}_{5}}$ se correlacionó $(\mathrm{P}<$ $0,05)$ negativamente con la concentración de clorofila "a" y positivamente con la concentración de amonio.

La estabilidad relativa de una agua es una medida indirecta de la carga orgánica de un agua (CATALAN, 1969) y se basa en el cálculo del tiempo necesario para que una muestra de agua decolore un volumen de una solución de azul de metileno. La decoloración es consecuencia del agotamiento de oxígeno causado por los procesos de biodegradación. La estabilidad es, pues, función directa del tiempo y se expresa en porcentaje (IMHOFF, 1969). Los resultados obtenidos de este ensayo muestra que el tiempo necesario para la decoloración del azul de metileno añadido a las muestras de agua de altitudes superiores a los 740 metros fue siempre por encima de los 30 días. Las aguas de las estaciones 4 de los ríos Genil y Monachil tardaron de 9 a 10 días y las aguas de las estaciones 5 de esos mismos ríos sólo necesitaron unos pocos minutos. Esto supone una estabilidad relativa del agua del $99,99 \%$ por encima de los 740 metros de altitud, del $90 \%$ para las aguas comprendidas entre los 740 metros y 620 metros y una estabilidad 


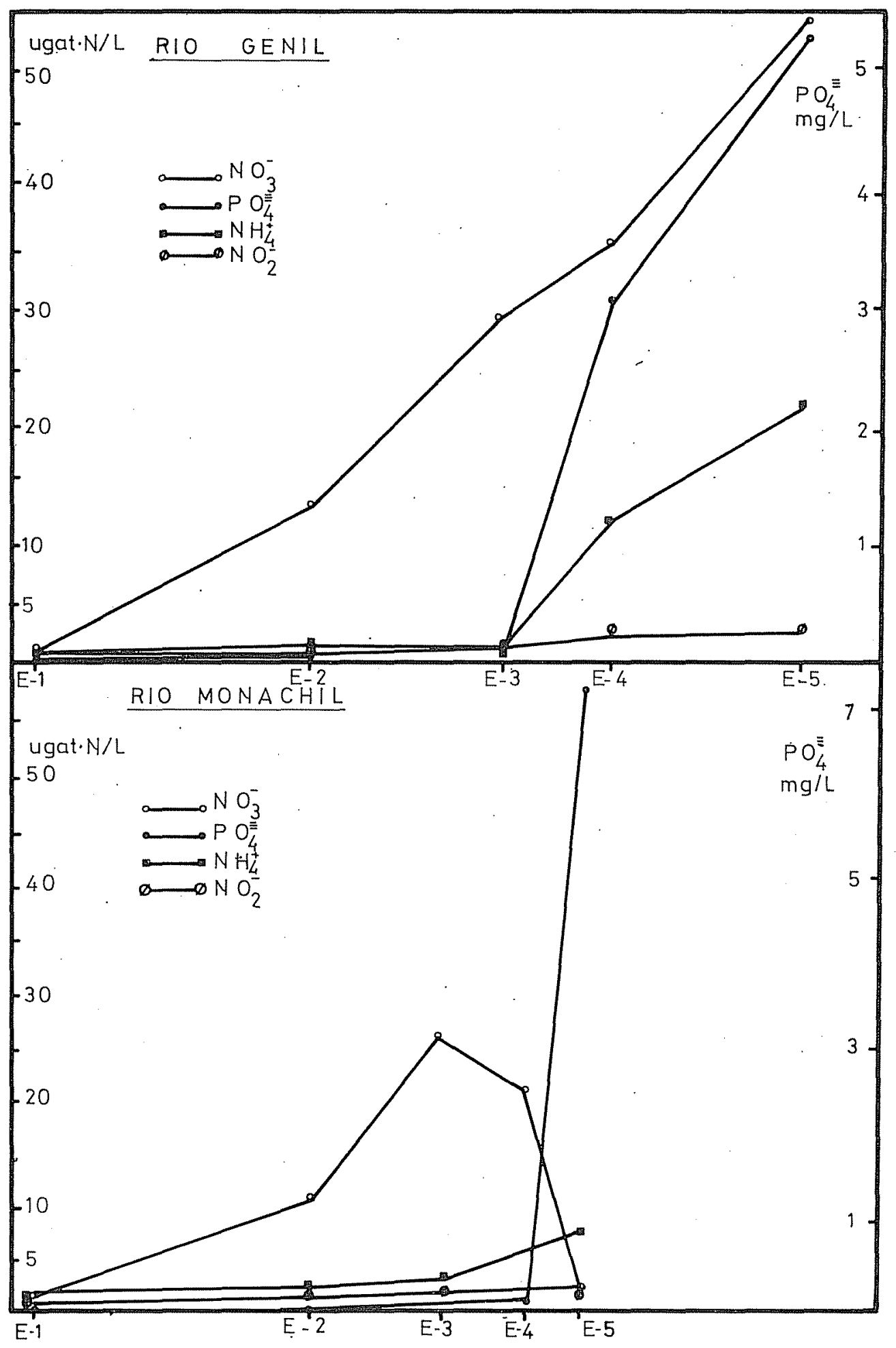

Fig. 3. Curvas de variación del nitrógeno y fósforo a lo largo de los ríos Genil y Monachil. 


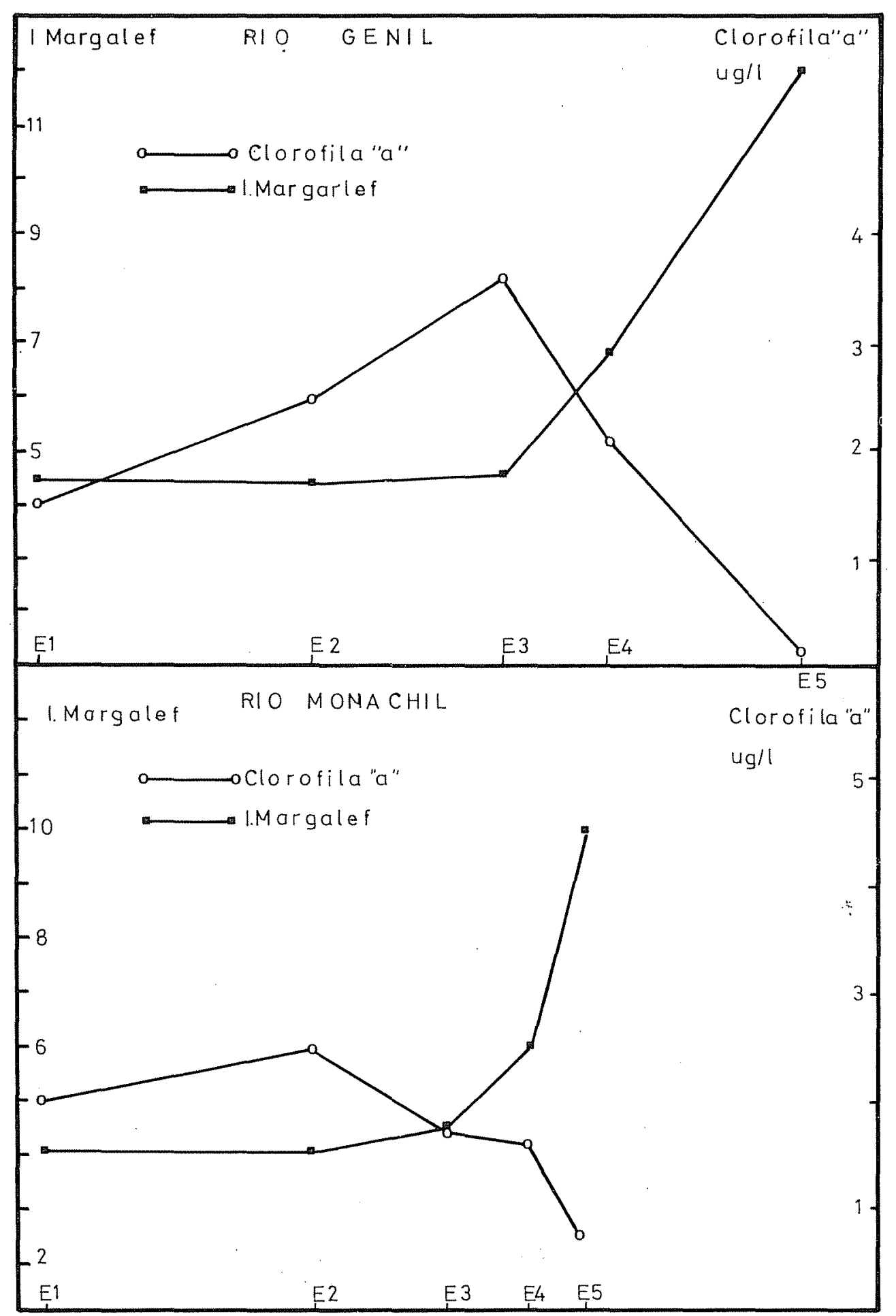

Fig. 4. Curvas de variación del índice de Margalef y de la clorofila "a" a lo largo de los ríos Genil y Monachil. 
relativa del $0,94 \%$ aguas abajo de 620 metros de altitud.

\section{PARAMETROS BIOTICOS}

Los valores medios de $E$. coli, oscilaron entre 0,073 , estación del río Chico, y 12.333 $\mathrm{NMP} / \mathrm{ml}$ (Número Más Probable por mililitro), en la estación 5 del rio Genil, aguas abajo de Granada capital. El análisis de la varianza mostró una clara significación de las diferencias entre altitudes, pero no, en cambio, entre períodos de muestreo ni entre los diferentes rios estudiados. El comportamiento general fue el de un progresivo enriquecimiento de las aguas en $E$. coli desde la primera estación de muestreo a la última, independientemente del río y del período de muestreo. En altitudes superiores a $1.300 \mathrm{me}$ tros el $\mathrm{NMP} / \mathrm{ml}$ fue inferior a 0,4 , oscilando entre 0,4 y $10^{2}$ en altitudes comprendidas entre 800 y 1.300 metros. Entre 620 y 800 metros de altitud el $\mathrm{NMP} / \mathrm{ml}$ varió entre $10^{2}$ y $10^{4}$ y aguas abajo de 620 metros la densidad de $E$. coli fue superior a $10^{5} \mathrm{NMP} / \mathrm{ml}$. Hay que subrayar la excesiva concentración de $E$. coli en el tramo superior del río Monachil. En las estaciones 1 y 2 , respectivamente situadas a 1.600 y 1.200 metros se llegaron a medir valores de $\mathrm{NMP} / \mathrm{ml}$ de 15 , con una media para ambas estaciones, de 9,5.

La densidad de bacterias heterótrofas no mostró diferencias significativas entre los distintos ríos estudiados. Sin embargo, las diferencias entre los períodos de muestreo y las diferencias entre altitudes resultaron claramente significativas $(P<0,001)$, deduciéndose una mayor densidad bacteriana en razón inversa a la altitud y durante el período de muestreo invernal. En dicho período la densidad bacteriana osciló entre 140 colonias por $\mathrm{ml}$ y $3,2 \cdot 10^{5}$. En primavera se registraron los valores más bajos. Las muestras tomadas aguas arriba de 800 metros de altitud mostraron un número de colonias por $\mathrm{ml}$ inferior a 2.000. Entre 800 y 685 metros estuvo comprendido entre 2.000 y 3.000 mientras que entre 685 y 620 metros varió zntre $10^{4}$ y $10^{5}$. Aguas abajo de 620 metros il número de colonias fue superior a $3.10^{6}$.
Los valores del indice de pigmentos de Margalef fluctuaron entre 2,7 y 12. Este último valor fue medido en la estación 5 del río Genil, en primavera, coincidiendo con valores muy elevados de DQO y DBO y con unos valores de concentración de oxígeno disuelto $y$ de bacterias heterótrofas indicadores de una alta actividad descomponedora de materia orgánica. En estas circunstancias las condiciones para el desarrollo de la vida se hacen muy extremas, reduciéndose a microorganismos heterótrofos anaerobios y/o microaerobios. Los valores del índice mostraron un paulatino aumento desde la primera estación a la última (fig. 4). Por encima de 800 metros, en valor medio, los índices fueron siempre inferiores a 3,6. Entre 800 y 620 metros estuvieron comprendidos entre 3,6 y 9,5 y por debajo de los 620 metros fueron superiores 9,5. La clorofila "a" a partir de 800 metros, aguas abajo y a medida que las aguas se enriquecian de materia orgánica, sufrió un brusco descenso, especialmente en los ríos Genil y Monachil (fig. 4).

\section{DISCUSION}

De los resultados analizados se deduce un estado progresivo de deterioro de la calidad de las aguas corrientes de Sierra Nevada. Esta situación, que especialmente se acentúa aguas abajo de 800 metros de altitud, llega hasta el punto de calificar a las aguas como no aptas para un elevado porcentaje de usos potenciales (ROPERO \& CANTERAS, 1981).

En primer lugar, se lleva a cabo un aumento de la concentración de sales minerales como consecuencia de la naturalezá geológica de los suelos drenados por los ríos. Esta situación queda reflejada, en forma global, por las curvas de conductividad eléctrica del agua. En segundo lugar, a partir de 800 metros de altitud, aguas abajo, y de manera más acentuada en los ríos de la vertiente Noroeste: Genil y Monachil, comienza a hacerse notar la influencia de la actividad humana. Las curvas de $\mathrm{DBO}_{5}$ y de DQO sufren bruscos aumentos como consecuencia de las entradas de elevadas cantidades de 
materia orgánica. La degradación de esta materia produce en los ríos:

1) Un gran desarrollo de la comunidad descomponedora, constituida en los ecosistemas acuáticos fundamentalmente por las bacterias heterótrofas.

2) Una fuerte disminución de la concentración de oxígeno, como consecuencia de la actividad bacteriana, y una elevación de la concentración de nutrientes.

3) Un deterioro de la comunidad productora como resultado de los efectos negativos que la materia orgánica ejerce sobre la clorofila "a" (NIETO, 1967; MARGALEF, 1974) que cae rápidamente, a partir de los 800 metros de altitud, mientras se eleva el índice de pigmentos de Margalef.

El análisis de componentes principales efectuado (ver MATERIAL Y METODOS) redujo la información de partida a cinco ejes que explican, en conjunto, más del

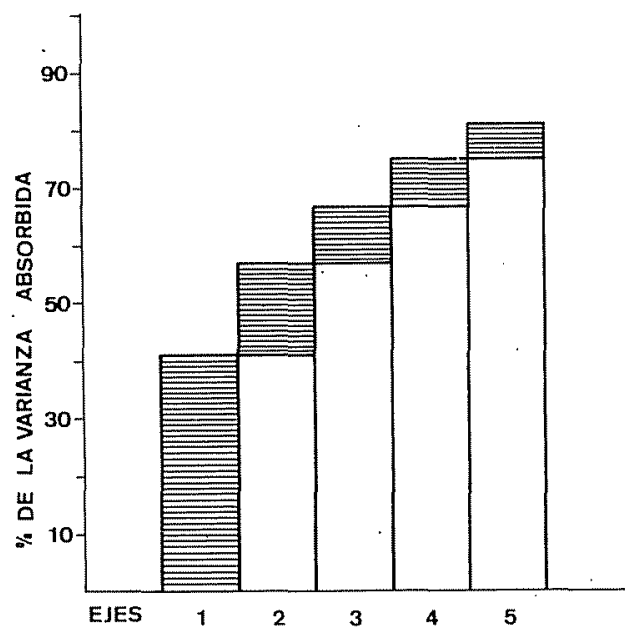

Fig. 5. Porcentaje de varianza absorbida por cada componente.

TABLA II. Matriz de factores de carga para los componentes principales.

VARIABLES
Sodio
DQO
Turbidez
Potasio
DBO5
Déficit de oxígeno
Oxigeno
Bacterias h.
Conductividad
Nitritos
Indice de Margalef
Alcalinidad
Sulfatos
Magnesio
Calcio
Temperatura
Escherichia coli
p4
Caudal
Velocidad
Altitud
Amonio
Fosfatos
Clorofila "a"

COMPONENTES

0,970

0,000

0,000

0,000

0,969

0,666

0,000

0,000

0,950

0,883

0,880

0,857

0,787

0,751

0,650

0,610

0,000

0,000

0,000

0,000

0,000

0,000

0,000

0,000

0,000

0,000

0,278

0,000

0,270

0,525

0,000

0,380

0,000

0,000

0,000

0,000

0,480

0,000

0,000

0,000

0,000

0,000

0,000

0,000

0,000

0,000

0,000

0,000

0,437

0,000

0,000

0,945

0,000

0,000

0,915

0,000

0,731

0,000

0,000

0,000

0,000

0,835

0,000

0,000

0,419

0,000

0,000

0,703

0,357

0,000
0,292

0,000

0,455

0,000

0,000

0,000

0,000

0,000

0,000

0,633

0,269

0,350

0,000

0,000

0,422

0,000

0,000

0,000

0,000

0,000

0,000

0,000

0,000

0,000

0,000

0,000

0,000

0,000

0,000

0,000

0,000

0,000

0,000

0,000

0,000

0,000

0,767

0,540

0,000

0,000

0,000

0,000

0,000 . 
$80 \%$ de la varianza original (fig. 5). Los factores de carga de cada una de las variables sobre estos cinco ejes se presentan en la tabla II. El primer eje estuvo gobernado positivamente por las siguientes variables: DQO, $\mathrm{DBO}_{5}$, déficit de oxígeno, nitritos, sodio, potasio, conductividad eléctrica y bacterias heterótrofas, y negativamente por la concentración de oxígeno disuelto. Se trata de variables relacionadas con la materia orgáni$\mathrm{ca}$, es decir, que aumentan o disminuyen con variaciones en la carga orgánica de las aguas. Los iones calcio y magnesio y la alcalinidad total definieron al segundo eje principal, quedando el tercero exclusivamente determinado por la concentración de $E$. coli. Por último, los ejes cuarto y quinto quedaron respectivaniente relacionados con el pH y la velocidad de la corriente.

Por todo ello concluimos que las principales tendencias de variación que actualmente están influyendo sobre las aguas corrientes de Sierra Nevada, deducidas de los factores de carga de la tabla II son:

1) Contaminación de origen orgánico

2) Mineralización de las aguas como consecuencia de la naturaleza geológica de los terrenos drenados por los ríos.

3) Contaminación de origen fecal

4) Grado de acidez del agua

5) Velocidad de la corriente

En función de estos criterios se puede distinguir en los ríos tres zonas:

- Primera: Constituida por las estaciones ubicadas en la cabecera de los ríos, caracterizada por la alta velocidad de la corriente y un $\mathrm{pH}$ próximo a la neutralidad.

- Segunda: Comprendida por las estaciones intermedias (entre 1.000 y 800 metros de altitud), caracterizada por la mineralización de las aguas en función de las zonas drenadas.

- Tercera: Estaciones aguas abajo de los 800 metros, caracterizada por una fuerte contaminación orgánica y fecal.

BIBLIOGRAFIA

BMDP. 1979. Institute of Health Sciencies. Universidad de California.

CATALAN, J.G. 1969. Quimica del agua, Blume. Madrid.

CHING CHUN LI. 1969. Introducción a la estadistica experimental. Omega. Barcelona.

GOLTERMAN, H.L. 1969. Methods for chemical analysis of fresh waters. Blackwell. Ox ford.

GRAYBILL, S.A. 1961. An introduction to lineat statistical models. McGraw-Hill. London.

GUINEA, J.; SANCHO, J.\& PARES, R. 1979. Análisis microbiológico de aguas. Omega. Barcelona.

HARRIGAN, W.F. \& McCANCE. 1968. Métodos de laboratorio en Microbiología. Academia. León.

IMHOFF, K. 1969. Manual de saneamiento de poblaciones. Blume. Madrid.

MARGALEF, R., 1974. Ecología. Omega. Barcelona.

MARGALEF, R.; PLANAS, D.; ARMENGOL, J.; VIDAL, A.; PRAT, N.; GUISET, A.: TOJA, J. \& ESTRADA, M. 1976. Limnología de los embalses españoles. Secretaría técnica del M.O.P. Madrid.

NEEDHAM, J. \& NEEDHAM, P. 1978. Los seres vivos en las aguas dulces. Reverté. Barcelona.

NIETO, M. 1967. Pigmentos como indicadores ecológicos en las aguas corrientes del centro de España. Tesis doctoral. Universidad de Madrid.

RODIER, J. 1978. L'analise de l'eau. Eaux naturelles, eaux residuales, eau de iner. Dunod. Paris.

RODINA, A. 1972. Methods in Aquatic Microbiology. University Park Press. Baltimore.

ROPERO, G. \& CANTERAS, J.C. 1981. Calidad de las aguas corrientes de Sierra Nevada. VIII Congreso Nacional de Microbiología. Madrid.

ROS, J. 1979. Prácticas de Ecología. Omega. Barcelona.

SCHWOERBEL, J. 1975. Métodos en hidrobiolo gía. Blume. Madrid.

SOROKIN, I. \& KADOTA, H. 1972. Microbial production and descomposition in fresh water Blackwell. Oxford. 


\begin{tabular}{|c|c|c|c|c|c|c|c|c|}
\hline & & RIO & GENIL & & & RIO & POQUEIR & \\
\hline & $E-1$ & $E-2$ & $E-3$ & $E-4$ & $E-5$ & $E-1$ & $E-2$ & $E-3$ \\
\hline $2(\mathrm{mg} / \mathrm{I})$ & 11,03 & 10,90 & $10: 07$ & 5,97 & 1,98 & 11,35 & $11 ; 09$ & 10,90 \\
\hline $\mathrm{BO}_{5}\left(\mathrm{mgO}_{2} / \mathrm{I}\right)$ & 0,92 & 1,47 & 2,18 & 8,57 & 15,34 & 1,21 & 3,52 & 3,46 \\
\hline $\mathrm{DQO}^{5}\left(\mathrm{mgO}^{2} / 1\right)$ & 1,87 & 8,53 & 6,40 & 43,00 & 74,03 & 7,63 & 17,07 & 15,07 \\
\hline Deficit $\sigma_{2}$ & 0,94 & 0,18 & 0,13 & 4,43 & 8,45 & 0,68 & 0,16 & 0.18 \\
\hline $\mathrm{Ca} \quad(\mathrm{mg} / \mathrm{I})^{2}$ & 93,30 & 105,70 & 105,1 & 111,0 & 134,00 & 52,40 & 48,20 & 41,80 \\
\hline $\operatorname{Mg}(\mathrm{mg} / \mathrm{l})$ & 4,40 & 9,80 & 21,50 & 23,20 & 32,70 & 5,60 & & 7,80 \\
\hline $\mathrm{K} \cdot(\mathrm{mg} / \mathrm{l})$ & 7,00 & 7,50 & 9,10 & 13,40 & 20,60 & 2,30 & 70 & 7,70 \\
\hline $\mathrm{Na} \quad(\mathrm{mg} / \mathrm{l})$ & 8,70 & 12,10 & 14,20 & $20.80^{\circ}$ & 36,40 & 12,80 &, 00 & 7,90 \\
\hline so $(\mathrm{mg} / 1)$ & 14,70 & 35,20 & 51,70 & 83,60 & 199,00 & 12,00 &, 30 & 12,00 \\
\hline $\mathrm{SiO}_{3}(\mathrm{mg} / \mathrm{I})$ & 0,22 & 0,17 & 0,15 & 0,29 & 0,29 & 0,20 & 0,32 & 0,20 \\
\hline $\mathrm{Cl}{ }^{3}(\mathrm{mg} / \mathrm{l})$ & 5,90 & 10,00 & 42,50 & 425,0 & 591,00 & 2,34 & 0,00 & 2,30 \\
\hline $\mathrm{NO}_{3}(\mathrm{mg} / \mathrm{l})$ & 0,03 & 0,52 & 1,83 & 2,19 & 3,40 & 0,08 & 0,97 & 0,90 \\
\hline $\mathrm{NO}_{2}^{3}(\mathrm{mg} / \mathrm{l})$ & 0,00 & 0,01 & 0,04 & 0,09 & 0,11 & 0,02 & 0,02 & 0,02 \\
\hline $\mathrm{NH}^{2}(\mathrm{mg} / \mathrm{I})$ & 0,01 & 0,03 & 0,02 & 0,02 & 0,40 & 0,00 & 0,01 & 0,00 \\
\hline $\mathrm{PO}_{4}^{4}(\mathrm{mg} / \mathrm{l})$. & 0,02 & 0,06 & 0,01 & 3,05 & 5,27 & 0,00 & 0,05 & 0,03 \\
\hline$\frac{\operatorname{col} i}{\mathrm{NMP} / \mathrm{mI}}$ & 0,17 & 0,53 & 9,50 & 150 & $123 \cdot 10^{3}$ & 0,28 & 51,5 & 37,3 \\
\hline $\begin{array}{l}\text { Bacterias h. } \\
(\operatorname{col} . / \mathrm{ml})\end{array}$ & 206 & 1140 & 2733 & $39.10^{4}$ & $355.10^{4}$ & 1027 & 1548 & 572 \\
\hline $\begin{array}{l}\text { Velocidad } \\
(\mathrm{m} / \mathrm{s})\end{array}$ & 1,17 & 0,60 & 0,55 & 0,89 & 0,23 & 0,69 & 0,86 & 1,17 \\
\hline $\begin{array}{l}\text { Caudal } \\
\left(\mathrm{m}^{3} / \mathrm{s}\right)\end{array}$ & 2,77 & 0,82 & 0,77 & 0,89 & 0,20 & 0,60 & 0,63 & 1,55 \\
\hline $\begin{array}{l}\text { Conduct. } \\
(\mu \mathrm{Mhos} / \mathrm{cm})\end{array}$ & 73,7 & 173,0 & 316,0 & 480,0 & 674,0 & 97,3 & 171,0 & 116,0 \\
\hline $\mathrm{T} O \mathrm{C}$ & 6,3 & 9,4 & 13,0 & 12,1 & 12,0 & 6,1 & 8,8 & 9,4 \\
\hline $\begin{array}{l}\text { Alcalini. } \\
\left(\mathrm{mg} / 1 \mathrm{CO}_{3} \mathrm{H}\right)\end{array}$ & 44,3 & 86,2 & 169,0 & 243,0 & 220,0 & 58,9 & 73,2 & 67,9 \\
\hline I: Margàlef & 3,4 & 3,4 & 3,5 . & 5,9 & 11,0 & 3,0 & 3,6 & 3,5 \\
\hline $\begin{array}{l}\text { Clorofila "a } \\
(\mu \mathrm{g} / \mathrm{l})\end{array}$ & 1,50 & 2,50 & 3,50 & 2,10 & 0,04 & 1,23 & 1,13 & 1,43 \\
\hline & 6,80 & 7,93 & 8,17 & 7,83 & 8,13 & 7,50 & 7,53 & 7,26 \\
\hline
\end{tabular}




\begin{tabular}{|c|c|c|c|c|c|c|c|}
\hline & & RIO & MONACHI & & & RIO I & DILAR \\
\hline & $E-1$ & $E-2$ & $E-3$ & $E-4$ & $E-5$ & $E-1$ & $E-2$ \\
\hline $\mathrm{O}_{2}(\mathrm{mg} / \mathrm{I})$ & 9,13 & 8,87 & 9,13 & $6 ., 97$ & 2,50 & 10,70 & 10,30 \\
\hline $\mathrm{DBO}_{5}\left(\mathrm{mgO}_{2} / 1\right)$ & 2,83 & 0,69 & 1,39 & 5,81 & 15,90 & 1,33 & 1,62 \\
\hline $\mathrm{DQO}^{5}\left(\mathrm{mgO}^{2} / \mathrm{I}\right)$ & 6,13 & 12,00 & 9,87 & 17,40 & 95,00 & 8,27 & 10,40 \\
\hline Deficit $0_{2}$ & 2,42 & 2,83 & 2,42 & 3,78 & 7,79 & 0,59 & 0,68 \\
\hline $\mathrm{Ca} \quad(\mathrm{mg} / \mathrm{I})$ & 111 & 104 & 54,20 & 51,30 & 47,50 & 91,10 & 42,10 \\
\hline $\mathrm{Mg} \quad(\mathrm{mg} / \mathrm{l})$ & 5,50 & $.76,20$ & 18,50 & 19,20 & 7,79 & 13,40 & 15,50 \\
\hline $\mathrm{K} \quad(\mathrm{mg} /$ & 7,10 & 4,80 & 8,80 & 14,10 & 28,50 & 8,30 & 12,80 \\
\hline $\mathrm{Na} \quad(\mathrm{mg} /$ & 0,70 & 16,10 & 19,00 & 23,40 & 138,0 & 7,70 & 13,40 \\
\hline so $(\mathrm{mg} / \mathrm{I})$ & 28,80 & 66,90 & 68,50 & 77,10 & 250,0 & 31,90 & 32,70 \\
\hline $\mathrm{SiO}_{3}^{4}(\mathrm{mg} / \mathrm{I})$ & 0,20 & 0,20 & 0,20 & 0,25 & 1,14 & 0,09 & 0,16 \\
\hline $\mathrm{Cl}{ }^{3}(\mathrm{mg} / \mathrm{I})$ & 4,10 & 13,00 & 33,10 & 145,00 & 570.00 & 0,00 & 5,90 \\
\hline $\mathrm{NO}_{3}(\mathrm{mg} / \mathrm{l})$ & 0,09 & 0,60 & 1,49 & 1,35 & 0,09 & 0,53 & 0,61 \\
\hline $\mathrm{NO}_{2}^{3}(\mathrm{mg} / \mathrm{I})$ & 0,02 & 0,04 & 0,06 & 0,08 & 0,07 & 0,01 & 0,03 \\
\hline $\mathrm{NH}_{4}^{2}(\mathrm{mg} / \mathrm{I})$ & 0,04 & 0,04 & 0,04 & 0,09 & 0,11 & 0,09 & 0,00 \\
\hline $\mathrm{PO}_{4}^{4}(\mathrm{mg} / \mathrm{I})$ & 0,17 & 0,06 & 0,44 & 1,16 & 7,20 & 0,01 & 0,03 \\
\hline$\frac{\mathrm{E} \cdot \operatorname{col} i}{\mathrm{NMP} / \mathrm{mI}}$ & 9,53 & 9,53 & 903 & 1367 & 11000 & 0,17 & 4,77 \\
\hline $\begin{array}{l}\text { Bacterias } h . \\
(\operatorname{col} . / \mathrm{mI})\end{array}$ & 4274 & 7407 & 9200 & 60833 & 750000 & 1080 & 1897 \\
\hline $\begin{array}{l}\text { Velocidad } \\
(\mathrm{m} / \mathrm{s})\end{array}$ & 0,57 & 1,03 & 0,46 & 0,42 & 0,25 & 0,93 & 0,85 \\
\hline $\begin{array}{l}\text { Caudal } \\
\left(\mathrm{m}^{3} / \mathrm{s}\right)\end{array}$ & 0,64 & 1,13 & 0,09 & 0,05 & 0,40 & 1,00 & $0 ; 41$ \\
\hline $\begin{array}{l}\text { Conduct. } \\
\text { (גMhos/cm) }\end{array}$ & 146 & 235 & 276 & 293 & 570 & 172 & 234 \\
\hline $\mathrm{T} \cong \mathrm{C}$ & 7,7 & 7,2 & 7,7 & 10,7 & 13,6 & 8,6 & 9,6 \\
\hline $\begin{array}{l}\text { Alcalini. } \\
\left(\mathrm{mg} / \mathrm{ICO}_{3} \mathrm{H}\right)\end{array}$ & 67,9 & 130 & 150 & 165 & $427^{\circ}$ & .127 & 112 \\
\hline I. Margălef & 3,1 & 3,0 & 3,5 & 5,2 & 10,0 & 3,0 & 3,4 \\
\hline $\begin{array}{l}\text { Clorofila "a } \\
(\mu \mathrm{g} / \mathrm{l})\end{array}$ & 4,01 & 4,53 & $3,89^{\circ}$ & 2,66 & 4,70 & 1,83 & 2,12 \\
\hline & 7,43 & 7,66 & 7,63 & 8,86 & 8,10 & $7,4 \ddot{3}$ & 7,50 \\
\hline
\end{tabular}


RIO A.BLANCAS

$$
\text { ह-1 }
$$$$
\mathrm{O}_{2}(\mathrm{mg} / \mathrm{l})
$$$$
\mathrm{DBO}^{5}\left(\mathrm{mgO}_{2} / 1\right)
$$$$
\text { Deficit } 8
$$$$
\mathrm{Ca} \quad(\mathrm{mg} / 1)^{2}
$$$$
\mathrm{Mg}(\mathrm{mg} / \mathrm{l})
$$$$
\mathrm{K} \text { (mg/l) }
$$$$
\mathrm{Na} \text { (mg/1) }
$$$$
\mathrm{SO}_{4}(\mathrm{mg} / \mathrm{I})
$$$$
\mathrm{sid}_{3}(\mathrm{mg} / \mathrm{I})
$$$$
\mathrm{Cl} 3(\mathrm{mg} / \mathrm{l})
$$$$
\mathrm{NO}_{3}(\mathrm{mg} / \mathrm{l})
$$$$
\mathrm{NO}_{2}^{3}(\mathrm{mg} / \mathrm{I})
$$$$
\mathrm{NH}_{4}^{2}(\mathrm{mg} / \mathrm{l})
$$$$
\mathrm{PO}_{4}^{4}(\mathrm{mg} / 1)
$$

\section{E.coli}

$\mathrm{NMP} / \mathrm{mI}$

Bacterias h.

(col./ml)

Velocidad

(m?s)

Caudal

$\left(\mathrm{m}^{3} / \mathrm{s}\right)$

Conducti.

( $\mu$ Mhos/cm)

$\mathrm{T}$ 으

Alcalini.

( $\mathrm{mg} / 1 \mathrm{CO}_{3} \mathrm{H}$ )

I. Margălef

Clorofila "a" $\mathrm{pH}$

E-1 E-2

7,44

0,00

3,05

3,72

72,40

26,80

3,00

22,80

14,40

0,14

16,00

0,02

0,00

0,00

0,00

8,24

0,29

3,62

3,06

176,0 .

28,90

4,80

10,00

13,30

0.13

10,60

0,23

0,00

0,00

0,03

0,10

41,2

548

0,56

0,67

0,08

0,23

405

381

9,1

8,6 .

24

3 ,

0,40

262

7,37

$3,3.8$

7,66
$E-3$

8,58

$.0,05$

4,96

3,09

214,0

27,20

7,30

9,40

58,60

0,29

10,60

0,80

$\cdot 0,01$

0,03

0,23

E-4

R. VERDE

R. CHICO

$98,3 \cdot 125$.

$\begin{array}{llll}548 & 1126 & 3806 & 2127\end{array}$

E-1

E-1

8,87

9,57

0,87

10,33

$=, 72$

9,63

1,84

0,70

1,51

138,0

29,00

3,60

11,60

69,00

0,25

44,90

64,3

3,40

4,70

6,50

6,80

0,17

7,10

0,18

0,01

0,02

0,03

5, 37

0,54

93,80

14,60

4,80

9,00

52,20

0,20

$1 ; 20$

0,18

0,00

0,01

0,01

0,15

0,00

0,01

0,37

0,07

0,30

0,61

581

735

0,36

0,18

0,23

0,44

419

343

0,04

0,06

10,9

12,2

47

137

203

208

8,2

10,2

3,6

3,5

45

144.

3,9

1,70

3,69

3,2

0,56

8,03

8,20

2, 44

7,70 